
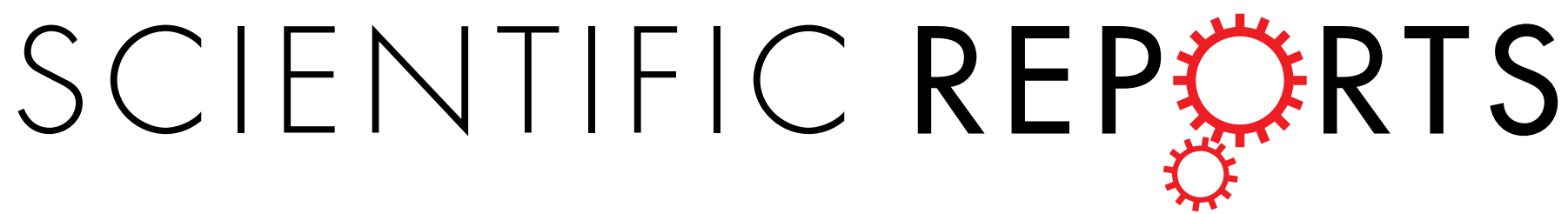

\title{
OPEN Gas-generated thermal oxidation of a coordination cluster for an anion- doped mesoporous metal oxide
}

Received: 20 July 2015

Accepted: 18 November 2015

Published: 18 December 2015

\author{
Kenji Hirai ${ }^{1}$, Shigehito Isobe ${ }^{2,3} \&$ Kazuki Sada $^{1}$
}

Central in material design of metal oxides is the increase of surface area and control of intrinsic electronic and optical properties, because of potential applications for energy storage, photocatalysis and photovoltaics. Here, we disclose a facile method, inspired by geochemical process, which gives rise to mesoporous anion-doped metal oxides. As a model system, we demonstrate that simple calcination of a multinuclear coordination cluster results in synchronic chemical reactions: thermal oxidation of $\mathrm{Ti}_{8} \mathrm{O}_{10}$ (4-aminobenzoate) ${ }_{12}$ and generation of gases including amino-group fragments. The gas generation during the thermal oxidation of $\mathrm{Ti}_{8} \mathrm{O}_{10}(4 \text {-aminobenzoate })_{12}$ creates mesoporosity in $\mathrm{TiO}_{2}$. Concurrently, nitrogen atoms contained in the gases are doped into $\mathrm{TiO}_{2}$, thus leading to the formation of mesoporous $\mathrm{N}$-doped $\mathrm{TiO}_{2}$. The mesoporous $\mathrm{N}$-doped $\mathrm{TiO}_{2}$ can be easily synthesized by calcination of the multinuclear coordination cluster, but shows better photocatalytic activity than the one prepared by a conventional sol-gel method. Owing to an intrinsic designability of coordination compounds, this facile synthetic will be applicable to a wide range of metal oxides and anion dopants.

Geochemical process coupled with gas generation is of great importance to the evolution of natural porous minerals. The porosity in the minerals is created by evaporation of gas bubbles. The gases comprised mostly of water steam, carbon dioxide but also contains a small amount of hydrogen sulphide, hydrogen fluoride and ammonia ${ }^{1}$. The anions in those gases react with minerals to be incorporated as anionic partners for metal ions ${ }^{2}$. Consequently, incorporation of anions and void formations in the minerals simultaneously occur, giving rise to natural porous minerals containing anions such as sulphur, fluorine and nitrogen.

Porous metal oxides represent promising materials for energy storage ${ }^{3}$, photocatalysis $^{4-5}$, and photovoltaics ${ }^{6-7}$ because of the large active surface area. By contrast, the control of chemical composition in metal oxides is also vital to these applications. In particular, incorporation of another anion into metal oxides, i.e. anion doping, provides excellent performance in ion-storage $e^{8}$ and photocatalytic reaction ${ }^{9-10}$. However, synthesis of porous metal oxides and anion doping have been individually developed. In that context, a crucial challenge in this research field is to coherently integrate these two processes. These considerations inspire us to mimic the geochemical process to establish a facile synthetic method for anion-doped porous metal oxides.

Coordination compounds, wherein metal ions and organic ligands are rationally varied ${ }^{11-16}$, are candidates for precursor to apply the gas-generated thermal oxidation. Indeed, coordination compounds are thermally oxidized into metal oxides by calcination ${ }^{17-20}$. On the other hand, organic molecules are fragmented to generate gases by intense heating ${ }^{21-22}$. In particular, gases containing reactive anions are generated by the fragmentation of organic functional groups, which potentially act as dopant sources. In general, however, the organic ligands of coordination compounds are removed by heating before reaching temperatures where metal oxides are formed. Because of the temperature gap, a calcination of coordination compounds gives metal oxides even without anion doping.

Our strategy to overcome the problem is to improve thermal stability of organic ligands by robust coordination bonding ${ }^{23}$ of carboxylates with a multinuclear metal cluster. As a model system, we design a multinuclear titanium coordination cluster comprised of a carboxylate ligand with a pendant amino-group. The carboxylate ligand is anchored by coordination bonding with the multinuclear titanium cluster until formation of metal oxides. Therefore, fragmentation of amino-group overlaps with thermal oxidation of the titanium coordination cluster.

${ }^{1}$ Department of Chemistry, Graduate School of Science, Hokkaido University, Kita 10 Nishi 8, Kita-ku, Sapporo, Hokkaido 060-0810, Japan. ${ }^{2}$ Creative Research Institution, Hokkaido University, Kita 21, Nishi 10, Kita-ku, Sapporo, Hokkaido 001-0021, Japan. ${ }^{3}$ Graduate School of Engineering, Hokkaido University, Kita 13, Nishi 8, Kita-ku, Sapporo, Hokkaido 060-8628, Japan. Correspondence and requests for materials should be addressed to K.H. (email: hiraikenji@sci.hokudai.ac.jp) or K.S. (email: sadatcm@mail.sci.hokudai.ac.jp) 


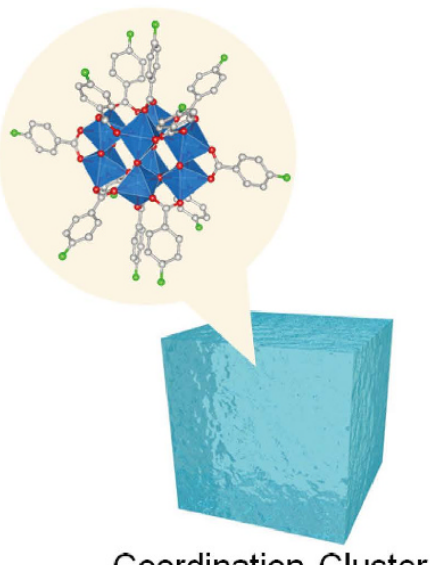

Coordination Cluster

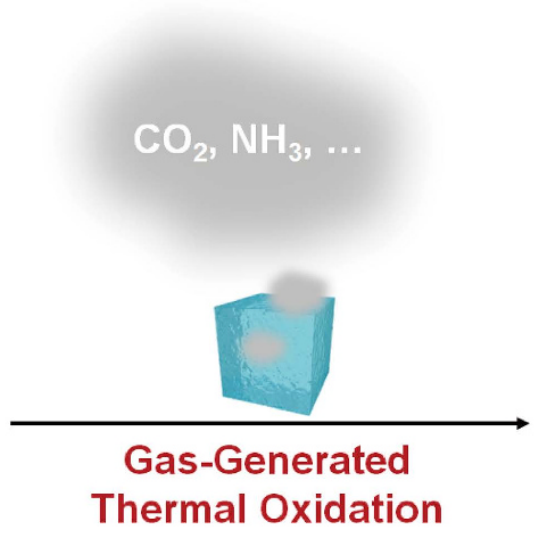

Mesoporous $\mathrm{N}$-doped $\mathrm{TiO}_{2}$

Figure 1. Schematic illustration of gas-generated thermal oxidation of a coordination cluster.

Consequently, $\mathrm{TiO}_{2}$ is formed under evaporation of gases containing nitrogen atoms, giving rise to $\mathrm{N}$-doped $\mathrm{TiO}_{2}{ }^{24-26}$ with permanent porosity. In other words, the porous $\mathrm{N}$-doped $\mathrm{TiO}_{2}$ can be obtained by a simple calcination of the coordination cluster.

Metal oxides doped with anion ${ }^{27-29}$ has attracted much attention because of potential applications of visible-light photocatalyst for water splitting ${ }^{30}$, pollutant degradation ${ }^{31-32}$ and solar energy conversion ${ }^{33-34}$. Porosity further improves the photocatalytic activity by increasing a surface area and improving the accessibility to catalytic active $\operatorname{sites}^{35}$. The mesoporous metal oxide has been fabricated by elaborate protocols, including templating method ${ }^{36-37}$, or particle assembly ${ }^{38-39}$. Sol-gel method is rather simple to synthesize mesoporous metal oxide, which can be easily combined with anion doping ${ }^{40-41}$. However, synthesis of mesoporous metal oxides via sol-gel method requires precise control of hydrolysis and condensation rates, which would conflict with anion doping approach. From simplicity of the protocol, calcination of coordination clusters will be an attractive strategy to fabricate anion-doped porous metal oxides (Fig. 1). Notably, coordination compounds can be rationally designed by a judicious choice of metal ions and organic ligands ${ }^{42}$. Therefore, the strategy presented here will be applicable to other types of metal oxides and anion dopants.

\section{Results}

We synthesized a titanium coordination cluster with 4-amino benzoic acid. A solvothermal reaction of titanium isopropoxide and 4-amino benzoic acid in acetonitrile gave cuboid crystals with a size of several hundred $\mu \mathrm{m}$. The resulting compound of $\mathrm{Ti}_{8} \mathrm{O}_{10}(4 \text {-aminobenzoate) })_{12}$ (1) consists of $\mathrm{Ti}_{8} \mathrm{O}_{10}$ cluster, where octanuclear titanium is linked by ten $\mu_{2}$-oxo bridges. The carboxyl groups of twelve 4 -aminobenzoate further bridge each titanium to each of its neighbouring titanium in a bidentate fashion (Fig. 2a-c).

As a reference, another titanium coordination cluster without amino-group, $\mathrm{Ti}_{8} \mathrm{O}_{8}$ (benzoate) ${ }_{16}^{43}$ (2), was synthesized by a solvothermal reaction of titanium isopropoxide and benzoic acid. The compound (2) consists of $\mathrm{Ti}_{8} \mathrm{O}_{8}$ ring-shaped cluster, where octanuclear titanium is linked by eight $\mu_{2}$-oxo bridges. The carboxyl groups of sixteen benzoate binds to titanium in a bidentate fashion from the axial and equatorial positions (Fig. 2d-f). Eight equatorial benzoate point up and down alternatively from the plane of $\mathrm{Ti}_{8} \mathrm{O}_{8}$ ring cluster, whereas the eight other axial benzoate point up and down perpendicularly.

Dozens of crystals of 1 and 2 were calcined at $480^{\circ} \mathrm{C}$ in air for 3 hours (heating rate: $8^{\circ} \mathrm{C} / \mathrm{min}$ ). The tiny crystalline particles with the size of $5 \mu \mathrm{m}$ were obtained by calcination of $\mathbf{1}$ and $\mathbf{2}$ (Figure S1). X-ray diffraction (XRD) pattern of calcined $\mathbf{1}$ and $\mathbf{2}$ corresponded to anatase $\mathrm{TiO}_{2}$, suggesting that $\mathbf{1}$ and $\mathbf{2}$ were converted into $\mathrm{TiO}_{2}$ (denoted as $\mathrm{TiO}_{2}-(\mathbf{1})$ and $\mathrm{TiO}_{2}-(\mathbf{2})$, respectively) (Fig. 3a).

$\mathrm{X}$-ray photon spectroscopy (XPS) was carried out to clarify the incorporation of nitrogen atoms in $\mathrm{TiO}_{2}$. A broad XPS peak of $\mathrm{N}_{1 \mathrm{~s}}$ was observed in $\mathrm{TiO}_{2}-(\mathbf{1})$ but not in $\mathrm{TiO}_{2}-(\mathbf{2})$, suggesting that nitrogen in $\mathrm{TiO}_{2}-(\mathbf{1})$ is originating from the amino group of 4 -aminobenzoate (Figure S2). The binding energy of $\mathrm{N}_{1 \mathrm{~s}}(398 \mathrm{eV})$ corresponded to anionic $\mathrm{N}^{-}$in Ti-O-N which is in the range typically observed for substitutional nitrogen doping into $\mathrm{TiO}_{2}{ }^{44-46}$. Furthermore, the binding energies of $\mathrm{Ti}_{2 \mathrm{p} 1 / 2}(464 \mathrm{eV})$ and $\mathrm{Ti}_{2 \mathrm{p} 3 / 2}(459 \mathrm{eV})$ well matched with those of Ti in N-doped $\mathrm{TiO}_{2}{ }^{47}$ (Fig. 3b,c). As shown in Figure S4, Raman spectra of $\mathrm{TiO}_{2}-(\mathbf{1})$ and $\mathrm{TiO}_{2}-(\mathbf{2})$ showed the characteristic blue shift of $\mathrm{E}_{\mathrm{g}(1)}$ band by nitrogen doping $\left(139.6 \mathrm{~cm}^{-1} \text { for } \mathrm{TiO}_{2^{-}}(2) \text { and } 144.0 \mathrm{~cm}^{-1} \text { for } \mathrm{TiO}_{2}-(1)\right)^{48}$. These results suggested that nitrogen originating from amino group was incorporated into $\mathrm{TiO}_{2}$ as a dopant, giving rise to $\mathrm{N}$-doped $\mathrm{TiO}_{2}$. The nitrogen concentration in $\mathrm{TiO}_{2}-(\mathbf{1})$ was estimated as $0.96 \%$.

The resulting $\mathrm{TiO}_{2}-(\mathbf{1})$ is yellow because of the nitrogen doping, whereas non-doped $\mathrm{TiO}_{2}$, including $\mathrm{TiO}_{2}-(2)$, is white (Fig. 3d). As expected, $\mathrm{TiO}_{2}-(\mathbf{1})$ showed absorption in the visible-light region (400-500 nm), but $\mathrm{TiO}_{2}-(\mathbf{2})$ absorbs only light in ultraviolet (UV) region (Fig. 3e). This is because nitrogen doping into $\mathrm{TiO}_{2}$ created a new energy level $\left(\mathrm{N}_{2 \mathrm{p}}\right.$ level) above the valence band maximum. The new absorption band in $400-450 \mathrm{~nm}$ corresponds to the energy gap between conductance band and $\mathrm{N}_{2 \mathrm{p}}$ level $(2.7 \mathrm{eV})$. These results suggest that $\mathrm{TiO}_{2}-(\mathbf{1})$ is able to work as photocatalyst under visible light. 
a

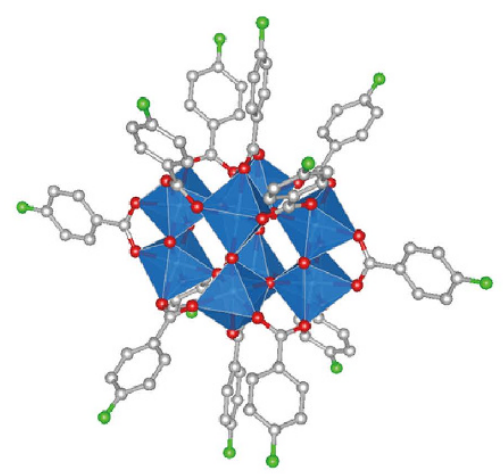

d

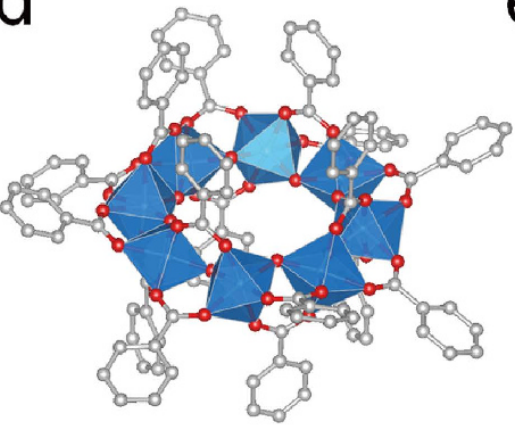

b

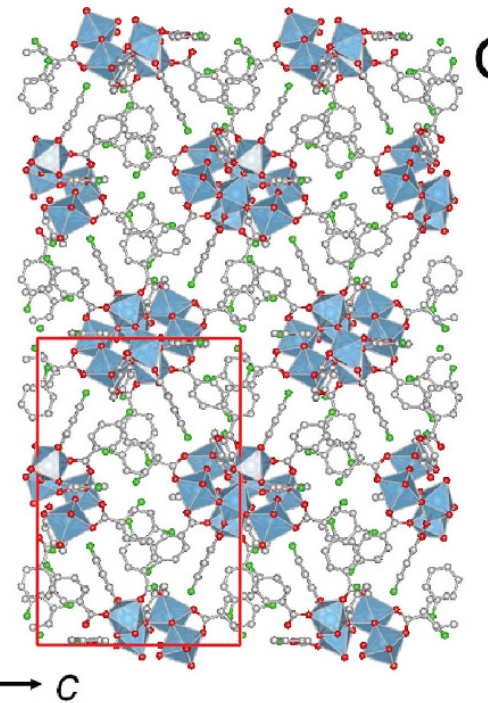

e

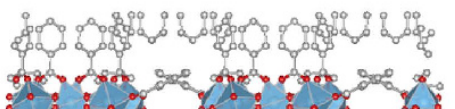

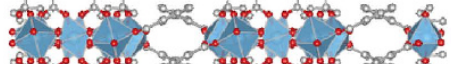

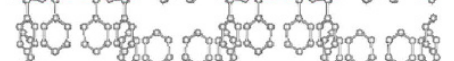
a

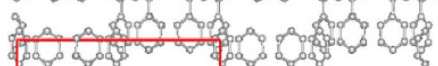
and

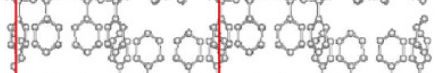
2000\% $\rightarrow$ a

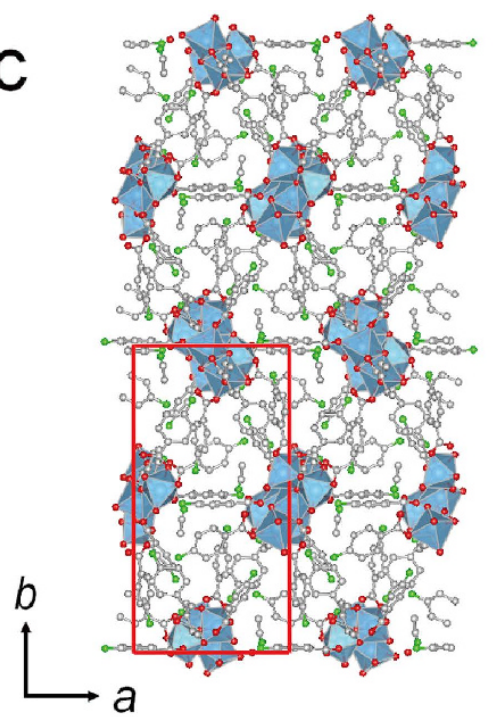

$f$

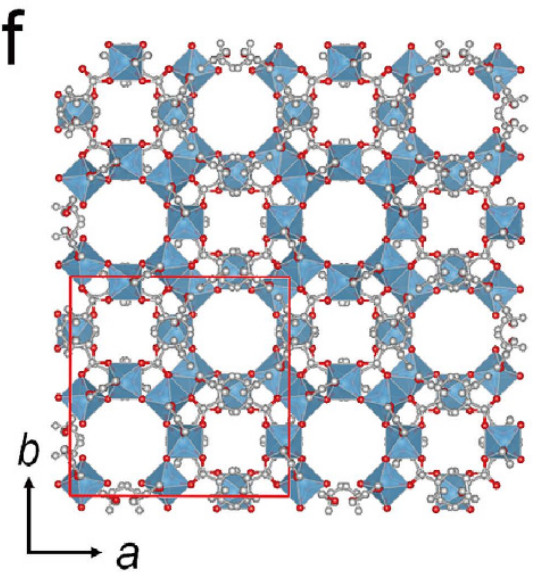

Figure 2. Crystal structures of titanium coordination clusters. Crystal structures of 1 and 2: (a) coordination geometry of $\mathbf{1}$. (b) view of $\mathbf{1}$ along $a$ axis and (c) $c$ axis. (d) coordination geometry of 2. (e) view of $\mathbf{2}$ along $b$ axis and (f) $c$ axis. The hydrogen atoms and solvent molecules are omitted for clarity. Each atoms of Ti, oxygen and carbon are coloured by blue, red and white. Ti is shown as a cation centred octahedral geometry.

Besides the nitrogen dope into $\mathrm{TiO}_{2}$, the porosity of $\mathrm{TiO}_{2}-(\mathbf{1})$ and $\mathrm{TiO}_{2}-(\mathbf{2})$ was evaluated by $\mathrm{N}_{2}$ adsorption (Figure S5a). The adsorption/desorption hysteresis was observed for $\mathrm{TiO}_{2}-(\mathbf{1})$ and $\mathrm{TiO}_{2}-(\mathbf{2})$ in the relative pressure $\left(P / P_{0}\right)$ range of $0.4-0.9$. This characteristic hysteresis is attributed to the mesopores of $\mathrm{TiO}_{2}$. The gradual adsorption in the hysteresis region, classified as $\mathrm{H} 2$ type adsorption, suggested mesopores with ununiform size and shape. The pore-size distribution, based on the desorption branch of the isotherm, was estimated by Barret, Joyner, and Halender $(\mathrm{BJH})$ method, assuming a cylindrical pore model. The pore sizes of $\mathrm{TiO}_{2}-(\mathbf{1})$ and $\mathrm{TiO}_{2}-(\mathbf{2})$ were calculated to be around $4 \mathrm{~nm}$ (Figure S5b). The mesopores of $\mathrm{TiO}_{2}-(\mathbf{1})$ were also observed by TEM (Figure S6). BET surfaces of $\mathrm{TiO}_{2}-(\mathbf{1})$ and $\mathrm{TiO}_{2}-(2)$ were estimated as $170.6 \mathrm{~m}^{2} / \mathrm{g}$ and $139.8 \mathrm{~m}^{2} / \mathrm{g}$, which were relatively large compared to those of metal oxides prepared by calcination of coordination compounds ${ }^{49,50}$.

The series of measurements indicated that simple calcination of the coordination cluster allows the synthesis of mesoporous $\mathrm{N}$-doped $\mathrm{TiO}_{2}$. To investigate the formation mechanism of mesoporous $\mathrm{N}$-doped $\mathrm{TiO}_{2}$, variable-temperature XRD (VT-XRD) and thermogravimetry with differential thermal analysis (TG-DTA) were carried out. As seen in VT-XRD, 1 was decomposed and the formation of $\mathrm{TiO}_{2}$ began over $400^{\circ} \mathrm{C}(\mathrm{Fig}$. $4 \mathrm{a})$. This result of VT-XRD was well matched with that of TG-DTA. TG-DTA showed the weight loss over $250^{\circ} \mathrm{C}$ because of evaporation of acetonitrile. Note that the exothermic peak was observed in DTA over $350^{\circ} \mathrm{C}$ (Fig. $4 \mathrm{~b}$ ). The exothermic peak is ascribed to the oxidation of titanium coordination clusters to form $\mathrm{TiO}_{2}$. The results of VT-XRD and TG-DTA suggested that $\mathrm{TiO}_{2}$ began to be crystallized over $350-400^{\circ} \mathrm{C}$.

Quadrupol mass spectroscopy (Q-MS) of 1 under heating further gave the insight into gas generation and mechanism of nitrogen doping. As seen in Fig. 4c, the gases of benzene, aniline, $\mathrm{HNO}_{3}$ and $\mathrm{CO}_{2}$ were generated in the temperature region of $300-480^{\circ} \mathrm{C}$, suggesting the decomposition of 4 -aminobenzoate. The organic ligand 

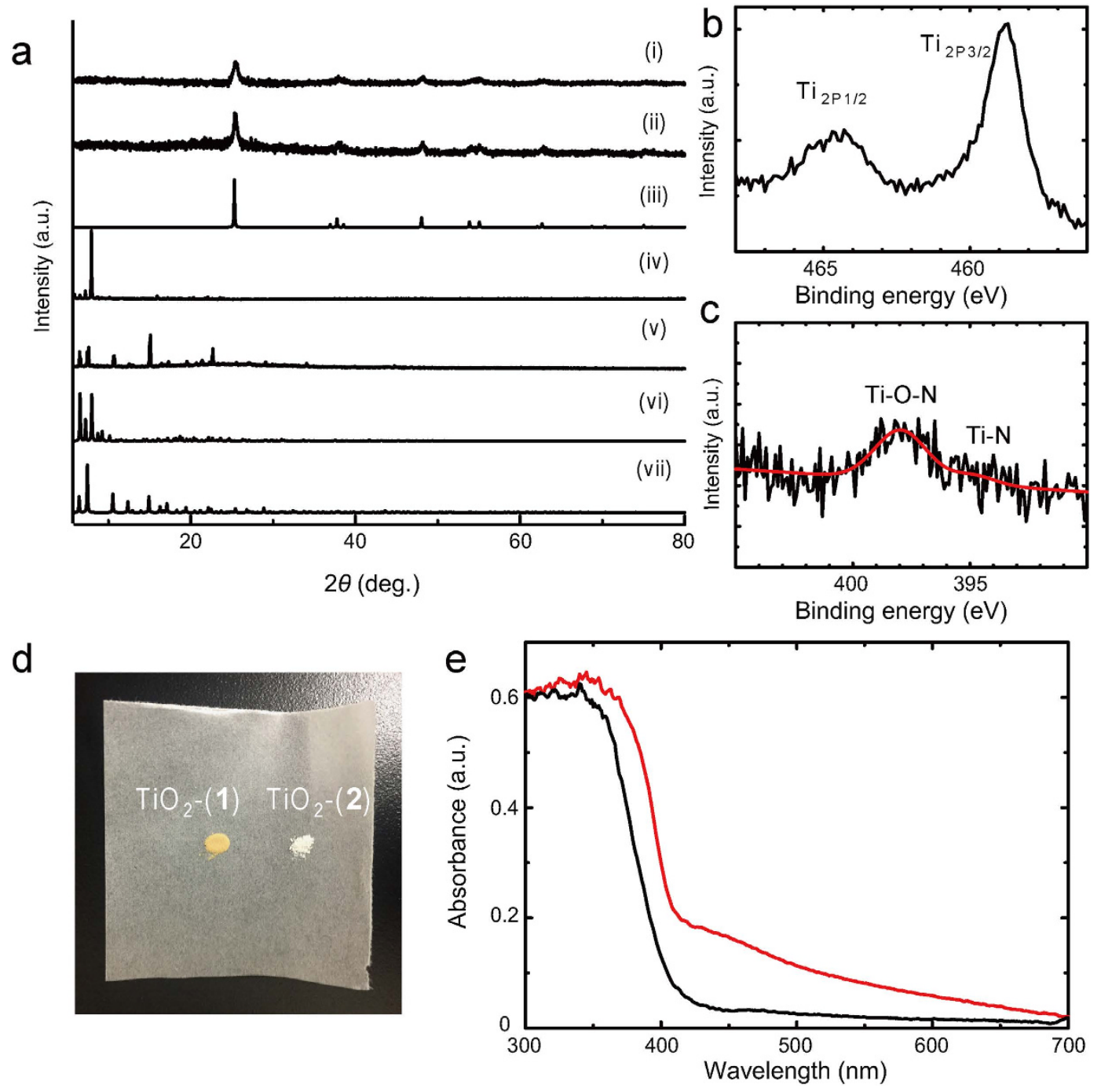

Figure 3. Spectroscopic characterization of $\mathrm{TiO}_{2}-(\mathbf{1})$ and $\mathrm{TiO}_{2}-(2)$. (a) $\mathrm{PXRD}$ of (i) $\mathrm{TiO}_{2}-(\mathbf{1})$, (ii) $\mathrm{TiO}_{2}-(2)$, (iii) Simulated $\mathrm{TiO}_{2}$, (iv) 1, (v) 2, (vi) simulated 1 and (vii) simulated 2. (b-c) XPS spectra of $\mathrm{TiO}_{2}-(\mathbf{1})$ for $\mathrm{Ti}_{2 \mathrm{p}}$ and $\mathrm{N}_{1 \mathrm{~s}}$ with fitting curves (red). The whole spectra is shown in supplementary information. (d) Photograph of $\mathrm{TiO}_{2}-(\mathbf{1})$ and $\mathrm{TiO}_{2}-(\mathbf{2})$, (e) UV-vis absorption spectra of $\mathrm{TiO}_{2}-(\mathbf{1})$ (red) and $\mathrm{TiO}_{2}-(2)$ (black).

was decomposed to generate gases concurrently with the formation of $\mathrm{TiO}_{2}$. In other words, $\mathrm{TiO}_{2}$ was crystalized during the generation of gases.

The decomposition of 4-aminobenzoate into benzene indicates that the covalent bond between the amino-group and phenyl ring was cleaved to generate the fragments containing nitrogen atoms ( $\mathrm{N}$-fragment). The generation of $\mathrm{N}$-fragment was also confirmed by the detection of $\mathrm{HNO}_{3} . \mathrm{HNO}_{3}$ was most likely formed by the oxidation of $\mathrm{N}$-fragments. The rest of $\mathrm{N}$-fragments reacted with $\mathrm{TiO}_{2}$ and nitrogen atoms were incorporated into $\mathrm{TiO}_{2}$ as a dopant.

This synchronic reaction was also observed in 2.2 was decomposed to begin the formation of $\mathrm{TiO}_{2}$ over $400^{\circ} \mathrm{C}$, which was characterized by VT-XRD and DT-XRD (Figure S7 and Figure S8). Q-MS measurement of 2 showed that benzoate was decomposed into gases of benzene and $\mathrm{CO}_{2}$ in $300-480^{\circ} \mathrm{C}$. Gas generation and formation of $\mathrm{TiO}_{2}$ were overlapped in the temperature range of $350-480^{\circ} \mathrm{C}$ (Figure S9). Nitrogen was not doped into $\mathrm{TiO}_{2}-(\mathbf{2})$ because of no nitrogen source (amino group) in the starting material of 2 . However, gas generation during the formation of $\mathrm{TiO}_{2}$ also resulted in the formation of mesoporous $\mathrm{TiO}_{2}$ (Figure $\mathrm{S} 10$ ).

Based on VT-XRD, TG-DTA, and Q-MS, we propose following the reaction mechanism of nitrogen doping. $\mathrm{Ti}_{8} \mathrm{O}_{10}$ (4-aminobenzoate) ${ }_{12}$ was decomposed to form $\mathrm{TiO}_{2}$ over $350^{\circ} \mathrm{C}$. 4 -aminobenzoate of 1 was decomposed into the gases of aniline, benzene, $\mathrm{CO}_{2}$ and $\mathrm{N}$-fragments. Nitrogen atoms in $\mathrm{N}$-fragments reacted with $\mathrm{TiO}_{2}$ to be incorporated into $\mathrm{TiO}_{2}$ as a dopant, forming $\mathrm{N}$-doped $\mathrm{TiO}_{2}$ (Fig. 5(i) molecular scale). The gases, including $\mathrm{CO}_{2}$, benzene, were generated concurrently with the formation of $\mathrm{TiO}_{2}$. Thus, gas evaporation during the formation of $\mathrm{TiO}_{2}$ created internal voids, leading to the formation of mesoporous $\mathrm{N}$-doped $\mathrm{TiO}_{2}$ (Fig. 5(ii) mesoscale). As mentioned above, the surface area of $\mathrm{TiO}_{2}-(\mathbf{1})$ and $\mathrm{TiO}_{2}-(2)$ are larger than the metal oxides synthesized by calcination 

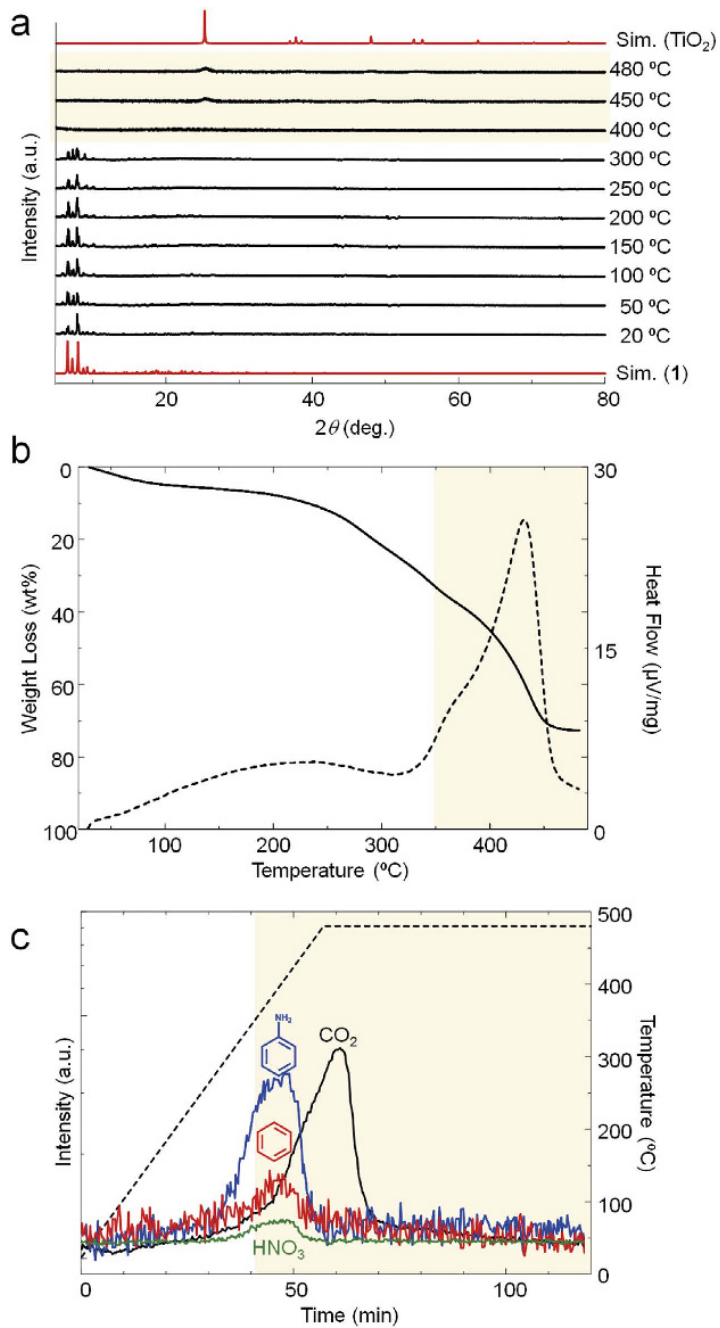

Figure 4. Time course experiments on calcination of the coordination cluster. (a) PXRD of 1 at variable temperature $20-480^{\circ} \mathrm{C}$. (b) TG analysis showing weight loss of 1 upon heating (black solid). DTA analysis showing exothermal peak around after $350^{\circ} \mathrm{C}$ (black dots). (c) Q-MS analysis with heating of $\mathbf{1}$ : aniline (m/z: 95, blue), benzene (m/z: 79, red), $\mathrm{CO}_{2}\left(\mathrm{~m} / \mathrm{z}: 44\right.$, black) and $\mathrm{HNO}_{3}(\mathrm{~m} / \mathrm{z}: 63$, green) were observed. Black dot line shows temperature of the sample cell. The yellow back ground indicates the temperature region for the formation of $\mathrm{TiO}_{2}$.

of extended coordination frameworks ${ }^{50}$. This is because the gas generation synchronized with formation of $\mathrm{TiO}_{2}$ created mesopores and significantly increased the surface area.

To evaluate the advantage of the new synthetic method, we synthesized mesoporous $\mathrm{N}$-doped $\mathrm{TiO}_{2}$ by a sol-gel method as a reference $\left(\mathrm{TiO}_{2} \text {-sg }\right)^{40,41}$. Isopropanol solution of titanium isopropoxide was mixed with aqueous solution of urea and nitric acid to prepare precursor sol. The resulting sol was calcined to synthesize mesoporous $\mathrm{N}$-doped $\mathrm{TiO}_{2}$. The nitrogen originating from urea was doped into $\mathrm{TiO}_{2}$. The mesoporosity and $\mathrm{BET}$ surface were evaluated by $\mathrm{N}_{2}$ adsorption (Figure S10). The mesoporosity is attributed to the interparticle voids as described in previous literatures ${ }^{41}$. As shown in Table $\mathrm{S} 1$, The $\mathrm{BET}$ surfaces of $\mathrm{TiO}_{2}-(\mathbf{1})$ and $\mathrm{TiO}_{2}-(\mathbf{2})$ were more than twice as large as that of $\mathrm{TiO}_{2}-\mathrm{sg}\left(\mathrm{TiO}_{2}-(1): 170.6 \mathrm{~m}^{2} / \mathrm{g}, \mathrm{TiO}_{2}-(2): 139.8 \mathrm{~m}^{2} / \mathrm{g}, \mathrm{TiO}_{2}-\mathrm{sg}: 59.24 \mathrm{~m}^{2} / \mathrm{g}\right)$. The crystallinity of $\mathrm{TiO}_{2}-(\mathbf{1})$ and $\mathrm{TiO}_{2}-(\mathbf{2})$ is nearly same as $\mathrm{TiO}_{2}-\mathrm{sg}$ (crystallite size; $\mathrm{TiO}_{2}-(\mathbf{1}): 13.4 \mathrm{~nm}, \mathrm{TiO}_{2}-(\mathbf{2}): 15.8 \mathrm{~nm}, \mathrm{TiO}_{2}-\mathrm{sg}$ : $16.4 \mathrm{~nm}$ ) (Figure S11 and Table S2). However, the concentration of nitrogen in $\mathrm{TiO}_{2}$-sg was slightly higher than $\mathrm{TiO}_{2}-(\mathbf{1})$ (Figure S12-13).

We evaluated the visible-light photocatalytic activity of $\mathrm{TiO}_{2}-(\mathbf{1}), \mathrm{TiO}_{2}-(\mathbf{2})$ and $\mathrm{TiO}_{2}$-sg by degradation of methylene blue $(\mathrm{MB})^{51,52}$. The crystals of $\mathrm{TiO}_{2}-(\mathbf{1}), \mathrm{TiO}_{2}-(\mathbf{2})$ or $\mathrm{TiO}_{2}$-sg were placed in a solution of $\mathrm{MB}$ and vigorously stirred under visible-light irradiation $(>410 \mathrm{~nm})$. The absorption intensity of $\mathrm{MB}$ decreased over time, showing the photocatalytic activity of $\mathrm{TiO}_{2}-(1)$ and $\mathrm{TiO}_{2}$-sg for the degradation of $\mathrm{MB}$ (Fig. 6 and Figure S14). The decrease rate of $\mathrm{TiO}_{2}-(2)$ and no catalysts were nearly same, suggesting that the intensity decrease of $\mathrm{MB}$ was attributed to not the adsorption of $\mathrm{MB}$ on $\mathrm{TiO}_{2}$ particles but the photocatalytic decomposition of $\mathrm{MB}$. Although the nitrogen concentration of $\mathrm{TiO}_{2}$-sg was higher than $\mathrm{TiO}_{2}-(\mathbf{1}), \mathrm{TiO}_{2}-(\mathbf{1})$ decomposed $\mathrm{MB}$ much faster than $\mathrm{TiO}_{2}$-sg. MB was completely decomposed by $\mathrm{TiO}_{2}-(\mathbf{1})$ in $150 \mathrm{~min}$, while only a half amount of MB was decomposed by $\mathrm{TiO}_{2}$-sg. Since nitrogen concentration of $\mathrm{TiO}_{2}-(\mathbf{1})$ is lower than $\mathrm{TiO}_{2}$-sg, the rapid degradation of $\mathrm{MB}$ is 


\section{(i) Molecular Scale}

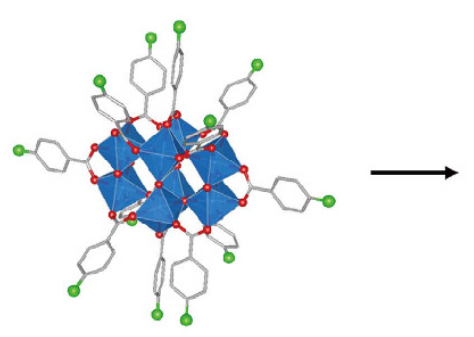

$\mathrm{Ti}_{8} \mathrm{O}_{8}\left(\text { benzoate- } \mathrm{NH}_{2}\right)_{12}$ (ii) Mesoscale

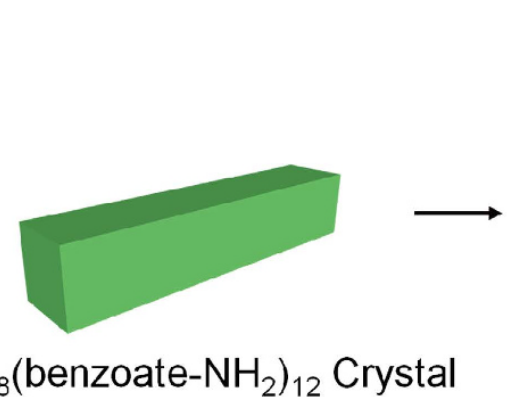

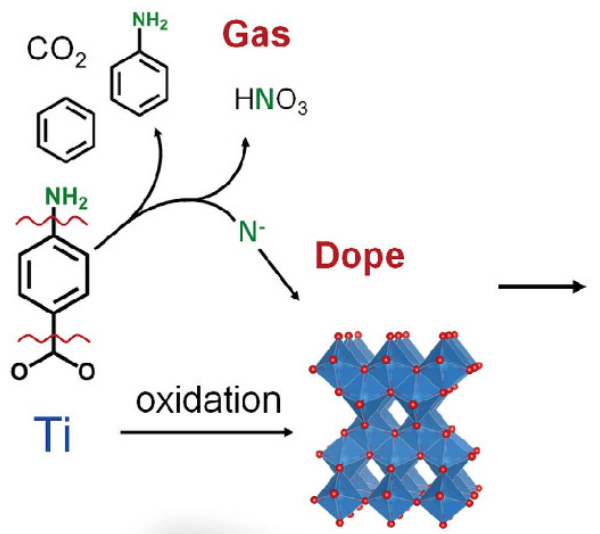

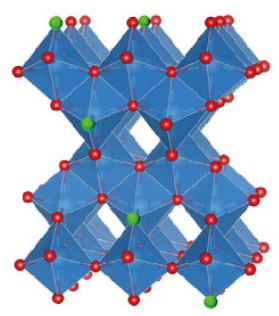

$\mathrm{TiO}_{2} \mathrm{~N}_{\mathrm{x}}$

Gas Generation

Figure 5. Schematic illustration of the reaction mechanism. Reaction scheme at (i) molecular scale and (ii) mesoscale: Coordination cluster of $\mathbf{1}$ is converted to mesoporous $\mathrm{N}$-doped $\mathrm{TiO}_{2}$.

most likely attributed to the large surface area of $\mathrm{TiO}_{2}-(\mathbf{1})$. The mesoporous $\mathrm{N}$-doped $\mathrm{TiO}_{2}$ can be easily prepared by calcination of the coordination cluster, but shows better photocatalytic activity than the one synthesized by a conventional sol-gel method.

\section{Conclusion}

In this contribution, we demonstrate a facile method for the synthesis of mesoporous anion-doped metal oxides. As a model system, we synthesized a multinuclear titanium coordination cluster with a pendant amino-group. A simple calcination of the coordination cluster resulted in synchronic reactions: thermal oxidation of the coordination cluster into $\mathrm{TiO}_{2}$ and gas generation including $\mathrm{N}$-fragments. The gas generation during the formation of $\mathrm{TiO}_{2}$ allows the introduction of mesopores. Furthermore, nitrogen atoms in N-fragments reacted with $\mathrm{TiO}_{2}$ to be incorporated as nitrogen dopant, thus leading to the formation of mesoporous $\mathrm{N}$-doped $\mathrm{TiO}_{2}$. The resulting mesoporous $\mathrm{N}$-doped $\mathrm{TiO}_{2}$ showed photocatalytic activity under visible light better than $\mathrm{TiO}_{2}$ prepared by a conventional sol-gel method, because of its larger surface area.

Notably, coordination clusters can be rationally designed by a choice of metal ions and organic ligands. Besides, doping amount can be potentially controlled by optimizing calcination conditions of coordination clusters (Figure S15). The synthetic and calcination protocols of the coordination clusters do not require specialized instruments. Therefore, coordination clusters as precursors will be a promising method for anion-doped porous metal oxides, which will offer significant benefits for the fabrication of light emitting diodes, ion storage batteries and heterogeneous catalysts.

\section{Methods}

Synthesis of $\mathrm{Ti}_{8} \mathrm{O}_{10}$ (4-aminobenzoate) $)_{12}$. A mixture of titanium(IV) isopropoxide $\left(5.1 \times 10^{-2} \mathrm{~mL}\right.$, $\left.1.72 \times 10^{-1} \mathrm{mmol}\right)$ and benzoic acid $(284 \mathrm{mg}, 2.33 \mathrm{mmol})$ was suspended in acetonitrile $(3 \mathrm{~mL})$ and heated in a teflon-lined steel bomb at $100^{\circ} \mathrm{C}$ for 1 day. The resulting crystals of $\mathrm{Ti}_{8} \mathrm{O}_{10}$ (4-amino benzoate) $)_{12}(\mathbf{1})$ were harvested by centrifuge and washed with acetonitrile three times.

Synthesis of $\mathrm{Ti}_{8} \mathrm{O}_{8}$ (benzoate) ${ }_{16}$. A mixture of titanium(IV) isopropoxide $\left(2.55 \times 10^{-2} \mathrm{~mL}\right.$, $\left.0.86 \times 10^{-1} \mathrm{mmol}\right)$ and benzoic acid $(142 \mathrm{mg}, 1.66 \mathrm{mmol})$ was suspended in acetonitrile $(3 \mathrm{~mL})$ and heated in a teflon-lined steel bomb at $100^{\circ} \mathrm{C}$ for 1 day. The resulting crystals of $\mathrm{Ti}_{8} \mathrm{O}_{8}$ (benzoate) ${ }_{16}(2)$ were harvested by centrifuge and washed with acetonitrile three times.

Calcination of 1 and 2. Crystals of 1 or 2 are placed in an $\mathrm{Al}_{2} \mathrm{O}_{3}$ boat (Sansho, SAB-995). The crystals are heated up to $480^{\circ} \mathrm{C}$ and kept at the temperature for 3 hours. 

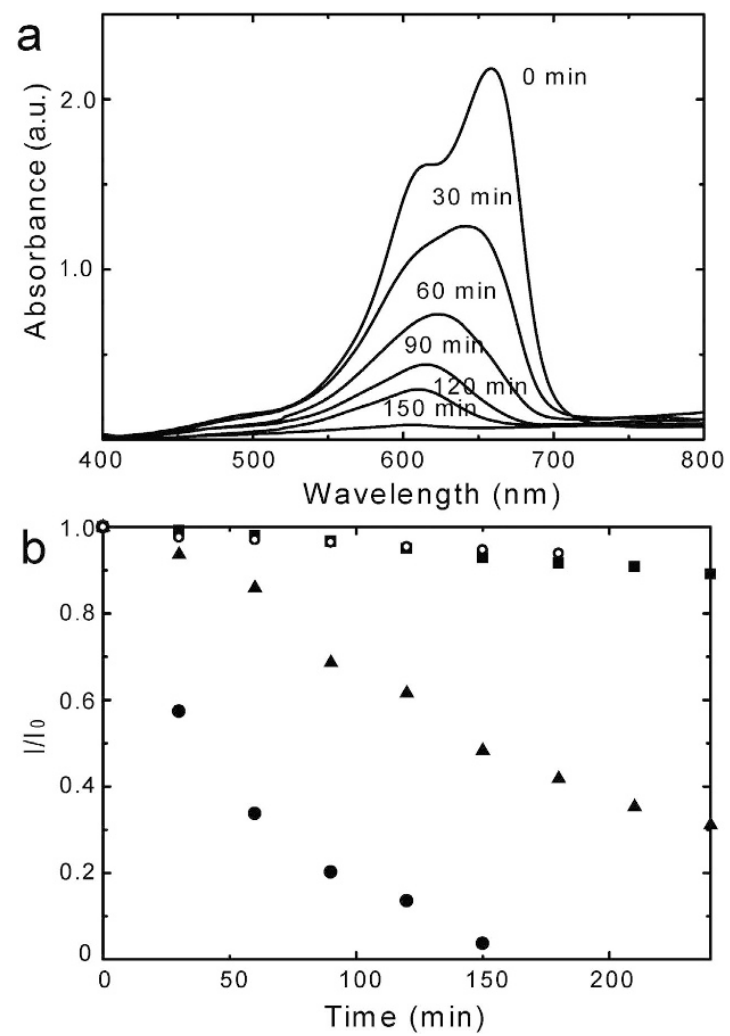

Figure 6. Photocatalytic activity of $\mathrm{N}$-doped $\mathrm{TiO}_{2}$. (a) UV-visible spectroscopic changes of methylene blue solution over $\mathrm{TiO}_{2}-(\mathbf{1})$, (b) chronological change of adoption intensity upon various photocatalysts under visible-light ( $>410 \mathrm{~nm}$ ) irradiation: no catalyst (circle), $\mathrm{TiO}_{2}-(\mathbf{1})$ (black dot), $\mathrm{TiO}_{2}-(2)$ (black square) and $\mathrm{TiO}_{2}$-sg (black triangle).

Synthesis of $\mathrm{N}$-doped $\mathrm{TiO}_{2}$ by Sol-Gel Method. N-doped $\mathrm{TiO}_{2}$ was prepare by a reported protocol with slight modifications ${ }^{40,41}$. Titanium(IV) isopropoxide $\left(5.94 \times 10^{-1} \mathrm{~mL}, 2.0 \mathrm{mmol}\right)$ was added to $10 \mathrm{ml}$ of isopropanol. Subsequently, urea $(120 \mathrm{mg}, 2.0 \mathrm{mmol})$ and nitric acid $(25 \mu \mathrm{l})$ were mixed with deionized water $(0.36 \mathrm{~mL})$. The solution of urea was dropped into the solution of titanium(IV) isopropoxide under stirring. The resulting sol was dried at $70^{\circ} \mathrm{C}$ and calcined at $400^{\circ} \mathrm{C}$ in air for 4 hours.

Photocatalytic Activity Test. $\quad \mathrm{TiO}_{2}(3 \mathrm{mg})$ was added to a quartz cell with $3 \mathrm{ml}$ of $\mathrm{MB}$ solution (20 ppm). A halogen lamp (SX-UI502M, USHIO SPAX INC.) was used as the light source. $400 \mathrm{~nm}$ cut-off filter was placed in front of the reactor.

X-ray Photon Spectroscopy (XPS). Dried powders of $\mathrm{TiO}_{2}-(1)$ and $\mathrm{TiO}_{2}-(2)$ were placed on a carbon conductive tape to avoid the powders from swirling in the air. XPS data were collected by JEOL Ltd. JPS-9200.

$\mathbf{N}_{2}$ Gas Adsorption. $\quad \mathrm{N}_{2}$ adsorption measurements were carried out by Quantachrome Autosorb 6AG. The BET surface area was determined by the multipoint BET method using the adsorption branch in the relative pressure $\left(P / P_{0}\right)$ range of $0.05-0.3$. The pore-size distribution was estimated by applying Barret, Joyner, and Halender $(\mathrm{BJH})$ method to the desorption branch of the isotherms.

Powder X-ray Diffraction (XRD). PXRD data were collected by Bruker D8 Advance ECO. Scherrer equation is applied to 110 diffraction of anatase $\mathrm{TiO}_{2}$ to estimate the average size of crystallite for $\mathrm{TiO}_{2}-(\mathbf{1}), \mathrm{TiO}_{2}-(\mathbf{2})$ and $\mathrm{TiO}_{2}$-sg. The instrumental broadening estimated by a standard sample $\left(\mathrm{Al}_{2} \mathrm{O}_{3}\right)$ is 0.042 .

Single Crystal X-ray Diffraction. Single-crystal XRD data collection $\left(5^{\circ}<2 \theta<55^{\circ}\right)$ was conducted at $223 \mathrm{~K}$ on Rigaku ACR-7R diffractometer Mo-K $\alpha$ radiation $(\lambda=0.7105 \AA)$ with Rigaku Mercury CCD system. The structures were solved by a direct method (SHELXS) and expanded using Fourier techniques. All calculations were performed using Yadokari-XG. Crystal data for $1: \mathrm{C}_{44} \mathrm{H}_{24} \mathrm{~N}_{7} \mathrm{O}_{17} \mathrm{Ti}_{4}$, monoclinic, space group $P 21 / n$ (no. 14), $a=12.430(5) \AA, b=24.443(9), c=16.163(6) \AA, \beta=93.367(6), V=4902.27 \AA^{3}, Z=4, T=223 \mathrm{~K}$, $\rho_{\text {calcd }}=1.510 \mathrm{gcm}^{-3}, \mu(\mathrm{Mo}-\mathrm{K \alpha})=0.706 \mathrm{~cm}^{-1} ; R_{1}=0.0957, \mathrm{w} R_{2}=0.1812, \mathrm{GOF}=1.055$. The hydrogen are severely disorder. (CCDC: 1406003).

Quadrupole Mass Spectrometer (Q-MS). The mass spectra of gases were collected by ULVAC APS-001 under heating of titanium coordination clusters (1) and (2). 
Other Apparatus. SEM images were collected by Phenom ProX. UV-vis absorption was measured by JASCO V-570. TEM image was collected by JEM-2100.

\section{References}

1. Giggenbach, W. F. [Chemical Composition of Volcanic Gases: Monitoring and Mitigation of Volcano Hazards] [221-256] (Springer, 1996).

2. Yokose, H., Lipman, P. W. \& Kanamatsu, T. Physical and Chemical Properties of Submarine Basaltic Rocks from the Submarine Flanks of the Hawaiian Islands. Marine Geology 219, 173-193 (2005).

3. Szeifert, J. M. et al. Ultrasmall Titania Nanocrystals and Their Direct Assembly into Mesoporous Structures Showing Fast Lithium Insertion. J. Am. Chem. Soc. 132, 12605-12611 (2010).

4. Kondo, J. N. et al. Synthesis, Mesostructure, and Photocatalysis of a Highly Ordered and Thermally Stable Mesoporous Mg and Ta Mixed Oxide. Chem. Mater. 16, 4304-4310 (2004).

5. Noda, Y., Lee, B., Domen, K. \& Kondo, J. N. Synthesis of Crystallized Mesoporous Tantalum Oxide and Its Photocatalytic Activity for Overall Water Splitting under Ultraviolet Light Irradiation. Chem. Mater. 20, 5361-5367 (2008).

6. Lee, M. M., Teuscher, J., Miyasaka, T., Murakami, T. N. \& Snaith, H. J. Efficient Hybrid Solar Cells Based on Meso-Superstructured Organometal Halide Perovskites. Science 338, 643-647 (2012).

7. Crossland, E. J. W. et al. Mesoporous $\mathrm{TiO}_{2}$ single crystals delivering enhanced mobility and optoelectronic device performance. Nature 495, 215-219 (2013).

8. Doeff, M. M. et al. Sulfur-Doped Aluminum-Substituted Manganese Oxide Spinels for Lithium-Ion Battery Applications. J. Electrochem. Soc. 150, A1060-A1066 (2003).

9. Cole, B. et al. M. Evaluation of Nitrogen Doping of Tungsten Oxide for Photoelectrochemical Water Splitting. J. Phys. Chem. C 112, 5213-5220 (2008).

10. Li, W., Li, J., Wang, X. \& Chen, Q. Preparation and water-splitting photocatalytic behavior of S-doped $\mathrm{WO}_{3}$. Appl. Surf. Sci. 263, 157-162 (2012).

11. Swiegers, G. F. \& Malefetse, T. J. New Self-Assembled Structural Motifs in Coordination Chemistry. Chem. Rev. 100, 3483-3537 (2000).

12. Yoshizawa, M., Klosterman, J. K. \& Fujita, M. Functional Molecular Flasks: New Properties and Reactions within Discrete, SelfAssembled Hosts. Angew. Chem. Int. Ed. 48, 3418-3438 (2009).

13. Hoskins, B. F. \& Robson, R. Design and construction of a new class of scaffolding-like materials comprising infinite polymeric frameworks of 3D-linked molecular rods. A reappraisal of the zinc cyanide and cadmium cyanide structures and the synthesis and structure of the diamond-related frameworks $\left[\mathrm{N}\left(\mathrm{CH}_{3}\right)_{4}\right]\left[\mathrm{CuIZnII}(\mathrm{CN})_{4}\right]$ and $\mathrm{CuI}\left[4,4^{\prime}, 4^{\prime \prime}, 4^{\prime \prime \prime}\right.$-tetracyanotetraphenylmethane] $\mathrm{BF}_{4} \bullet \mathrm{xC}_{6} \mathrm{H}_{5} \mathrm{NO}_{2}$. J. Am. Chem. Soc. 112, 1546-1554 (1990).

14. Kitagawa, S., Kitaura, R. \& Noro, S. Functional Porous Coordination Polymers. Angew Chem. Int. Ed. 43, 2334-2375 (2004)

15. Yaghi, O. M. et al. Reticular synthesis and the design of new materials. Nature 423, 705-714 (2003).

16. Serre, C. et al. Role of Solvent-Host Interactions That Lead to Very Large Swelling of Hybrid Frameworks. Science 315, 1828-1831 (2007).

17. Park, S. J., Cho, W. \& Oh, M. Monitoring and analysis of the seed-directed growth of micro-sized hexapod coordination polymers. CrystEngComm 12, 1060-1064 (2010)

18. Androš, L., Matković-Čalogović, D. \& Planinić, P. A series of compounds containing various (oxalato)tantalate(V) complex anions - synthesis, properties and the mixed-metal oxide formation via thermal decomposition. CrystEngComm 15, 533-543 (2013).

19. Bai, Z. et al. MOFs-derived porous $\mathrm{Mn}_{2} \mathrm{O}_{3}$ as high-performance anode material for Li-ion battery. J. Mater. Chem. A 3, 5266-5269 (2015).

20. Song, Y. et al. A Green Strategy to Prepare Metal Oxide Superstructure from Metal-Organic Frameworks. Sci. Rep. 5, 8401 (2015).

21. Guo, W., Leu, W. T., Hisao, S. H. \& Liou, G. S. Thermal degradation behaviour of aromatic poly(ester-amide) with pendant phosphorus groups investigated by pyrolysis-GC/MS. Polym. Deg. Stab. 91, 21-30 (2006).

22. Zuev, V. V., Zgonnik, P. V., Turkova, L. D. \& Shibaev, L. A. Thermal degradation of poly-p-nitrostyrene. Polym. Deg. Stab. 63, 15-17 (1999).

23. Guo, X. et al. A lanthanide metal-organic framework with high thermal stability and available Lewis-acid metal sites. Chem. Commun. 3172-3174 (2006).

24. Chen, X. \& Mao, S. S. Titanium Dioxide Nanomaterials: Synthesis, Properties, Modifications, and Applications. Chem. Rev. 107, 2891-2959 (2007).

25. Fujishima, A., Zhang, X. \& Tryk, D. A. TiO 2 photocatalysis and related surface phenomena. Surf. Sci. Rep. 63, 515-582 (2008).

26. Burda, C. et al. Enhanced nitrogen doping in $\mathrm{TiO}_{2}$ nanoparticles. Nano Lett. 3, 1049-1051 (2003).

27. Asahi, R., Morikawa, T., Ohwaki, T., Aoki, K. \& Taga, Y. Visible-Light Photocatalysis in Nitrogen-Doped Titanium Oxides. Science 293, 269-271 (2001).

28. González-Borrero, P. P. et al. A Energy-level and optical properties of nitrogen doped $\mathrm{TiO}_{2}$ : An experimental and theoretical study. Appl. Phys. Lett. 99, 221909 (2011).

29. Wang, B. et al. Anion-Doped $\mathrm{NaTaO}_{3}$ for Visible Light Photocatalysis. J. Phys. Chem. C 117, 22518-22524 (2013).

30. Liu, G. et al. Visible Light Responsive Nitrogen Doped Anatase $\mathrm{TiO}_{2}$ Sheets with Dominant $\{001\}$ Facets Derived from TiN. J. Am. Chem. Soc. 131, 12868-12869 (2009).

31. Li, D., Haneda, H. \& Ohashi, N. Visible-light-driven nitrogen-doped $\mathrm{TiO}_{2}$ photocatalysts: effect of nitrogen precursors on their photocatalysis for decomposition of gas-phase organic pollutants. Mater. Sci. Eng. B 117, 67-75 (2005)

32. Sano, T., Negishi, N., Koike, K., Takeuchi, K. \& Matsuzawa, S., Preparation of a visible light-responsive photocatalyst from a complex of $\mathrm{Ti}^{4+}$ with a nitrogen-containing ligand. J. Mater. Chem. 14, 380-384 (2004).

33. Liu, G. et al. A red anatase $\mathrm{TiO}_{2}$ photocatalyst for solar energy conversion. Energy Environ. Sci. 5, 9603-9610 (2012).

34. Lim, S. P., Pandikumar, A., Lim, H. N., Ramarah, R. \& Huang, N. M. Boosting Photovoltaic Performance of Dye-Sensitized Solar Cells Using Silver Nanoparticle-Decorated N,S-Co-Doped-TiO ${ }_{2}$ Photoanode. Sci. Rep. 5, 11922 (2015).

35. Amano, F., Ishinaga, E. \& Yamakata, A. Effect of Particle Size on the Photocatalytic Activity of $\mathrm{WO}_{3}$ Particles for Water Oxidation. J. Phys. Chem. C 117, 22584-22590 (2013).

36. Hall, A. S., Kondo, A., Maeda, K. \& Mallouk, T. E. Microporous Brookite-Phase Titania Made by Replication of a Metal-Organic Framework. J. Am. Chem. Soc. 135, 16276-16279 (2013).

37. Crossland, E. J. W. et al. Mesoporous $\mathrm{TiO}_{2}$ single crystals delivering enhanced mobility and optoelectronic device performance. Nature 495, 215-219 (2013).

38. Brezesinski, T., Wang, J., Polleux, J., Dunn, B. \& Tolbert, S. H. Templated Nanocrystal-Based Porous $\mathrm{TiO}_{2}$ Films for Next-Generation Electrochemical Capacitors. J. Am. Chem. Soc. 131, 1802-1809 (2009).

39. Chae, W. S., Lee, S. W. \& Kim, S. Y. R. Templating Route to Mesoporous Nanocrystalline Titania Nanofibers. Chem. Mater. 17, 3072-3074 (2005).

40. Mylsamy, M., Mahalakshmi, M., Murugesan, V. \& Subha, N. Enhanced photocatalytic activity of nitrogen and indium co-doped mesoporous $\mathrm{TiO}_{2}$ nanocomposites for the degradation of 2,4-dinitrophenol under visible light. Appl. Surf. Sci. 342, 1-10 (2015). 
41. Yu, B., Lau, W. M. \& Yang, J. Preparation and characterization of $\mathrm{N}-\mathrm{TiO}_{2}$ photocatalyst with high crystallinity and enhanced photocatalytic inactivation of bacteria. Nanotechnology 24, 335705 (2013).

42. Liu, J. et al. A novel series of isoreticular metal organic frameworks: realizing metastable structures by liquid phase epitaxy. Sci. Rep. 2, 921 (2012)

43. Frot, T. et al. $\mathrm{Ti}_{8} \mathrm{O}_{8}(\mathrm{OOCR})_{16}$, a New Family of Titanium-Oxo Clusters: Potential NBUs for Reticular Chemistry. Eur. J. Inorg. Chem. 36, 5650-5659 (2010).

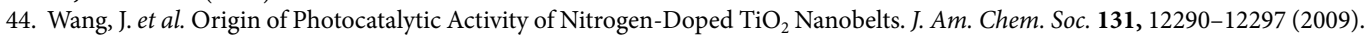

45. Irie, H., Watanabe, Y. \& Hashimoto, K. Nitrogen-Concentration Dependence on Photocatalytic Activity of $\mathrm{TiO}_{2-\mathrm{x}} \mathrm{N}_{\mathrm{x}}$ Powders. J. Phys. Chem. B 107, 5483-5486 (2003).

46. Jiang, X., Wang, Y. \& Pan, C. High Concentration Substitutional N-doped $\mathrm{TiO}_{2}$ Film: Preparation, Characterization, and Photocatalytic Property. J. Am. Ceram. Soc. 94, 4078-4083 (2011).

47. Sathish, M., Viswanathan, B., Viswanath, R. P. \& Gopinath, C. S. Synthesis, Characterization, Electronic Structure, and Photocatalytic Activity of Nitrogen-Doped $\mathrm{TiO}_{2}$ Nanocatalyst. Chem. Mater. 17, 6349-6353 (2005).

48. Siuzdak, K., Szkoda, M., Sawczak, M. \& Lisowska-Oleksiak, A. Novel nitrogen precursors for electrochemically driven doping of titania nanotubes exhibiting enhanced photoactivity. New J. Chem. 39, 2741-2751 (2015).

49. Zhang, $\mathrm{S}$. et al. $\mathrm{CuO} / \mathrm{Cu}_{2} \mathrm{O}$ porous composites: shape and composition controllable fabrication inherited from metal organic frameworks and further application in CO oxidation. J. Mater. Chem. A 3, 5294-5298 (2015).

50. Lü, Y. et al. MOF-Templated Synthesis of Porous $\mathrm{Co}_{3} \mathrm{O}_{4}$ Concave Nanocubes with High Specific Surface Area and Their Gas Sensing Properties. ACS Appl. Mater. Interfaces 6, 4186-4195 (2014).

51. Livraghi, S. et al. Origin of Photoactivity of Nitrogen-Doped Titanium Dioxide under Visible Light. J. Am. Chem. Soc. 128, 15666-15671 (2006).

52. Ren, R. et al. Controllable Synthesis and Tunable Photocatalytic Properties of $\mathrm{Ti}^{3+}$-doped $\mathrm{TiO}_{2}$. Sci. Rep. 5, 10714 (2015).

\section{Acknowledgements}

We thank Prof. Masako Kato, Dr. Atsushi Kobayashi and Mr. Yasuhiro Shigeta for assistance with the use of XRD and single crystal XRD. We also thank the open facility at Hokkaido University for the use of TEM, XPS and gas sorption instrument.

\section{Author Contributions}

K.H. conceived the project. K.H. and K.S. designed the experiments. K.H. performed synthetic and characterization experiments. S.I. performed Q.-M.S. measurements. K.H. and K.S. wrote the manuscript with edits made by all authors.

\section{Additional Information}

Supplementary information accompanies this paper at http://www.nature.com/srep

Competing financial interests: The authors declare no competing financial interests.

How to cite this article: Hirai, K. et al. Gas-generated thermal oxidation of a coordination cluster for an aniondoped mesoporous metal oxide. Sci. Rep. 5, 18468; doi: 10.1038/srep18468 (2015).

(c) (i) This work is licensed under a Creative Commons Attribution 4.0 International License. The images or other third party material in this article are included in the article's Creative Commons license, unless indicated otherwise in the credit line; if the material is not included under the Creative Commons license, users will need to obtain permission from the license holder to reproduce the material. To view a copy of this license, visit http://creativecommons.org/licenses/by/4.0/ 